\title{
Obstetric emergencies and transfusion needs in a Nigerian hospital
}

\begin{abstract}
Blood transfusion plays a significant role as a life-saving practice in emergency obstetrics and it is one of the essential components of comprehensive emergency obstetric care yielding a reduction in maternal mortality. While transfusion is commonly used to combat anaemia in obstetric practice, the majority of patients receiving transfusion are given to otherwise healthy women in response to undiagnosed obstetric hemorrhage. This study explores the need and blood transfusion rate among obstetrics patients at the University College Hospital (UCH), Ibadan to provide insight into the rationale behind such practices. This is a retrospective study of transfused obstetrics patients at UCH between the year 2009 and 2014. Information was extracted from their medical records using a pro-forma. Data were entered and analysed using SPSS version 20

Of the 21,208 births and 27,019 antenatal admissions during the study period, 597 patients were transfused and 565 medical records were analysed. Among these 565 patients, about two-thirds $412(72.9 \%)$ were un-booked patients. The transfusion rate was $2.2 \%$ and the commonest associated obstetrics complication requiring transfusion was anaemia $(65.5 \%)$ while $184(32.6 \%)$ were transfused because of postpartum hemorrhage. Other indications for transfusion were abruptio placentae, malaria and placenta previa. Patients who delivered via Caesarean Section (CS) had the highest transfusion rate of $62.4 \%$ and the estimated blood loss during delivery was significantly higher among the un-booked patients $(\mathrm{P}<0.01)$. More than two-thirds, 466(82.5\%) received whole blood while only $2(0.4 \%)$ received cryoprecipitate. About one-third of patients received single unit-transfusions. Though the overall obstetric transfusion rate was lower than that of comparable facilities, the transfusion rate among patients receiving CS was markedly high. Additionally, the majority of transfused obstetric patients had complications resulting in anaemia, while hemorrhage propagated the second highest number of cases requiring transfusion.
\end{abstract}

Keywords: blood transfusion, obstetrics, anaemia, hemorrhage
Volume 2 Issue 6 - 2016

\author{
Akingbola TS,' Bello OO' \\ 'Department of Haematology, University of Ibadan, Nigeria \\ ${ }^{2}$ Department of Obstetrics and Gynecology, University College \\ Hospital, Nigeria
}

Correspondence: Titilola S Akingbola, Department of Haematology, Faculty of Basic Medical Sciences, University College Hospital, University of Ibadan, Nigeria,Tel +2348037287188, Email tsakingbola@comui.edu.ng

Received: July 15, 2016 | Published: July 30, 2016
Abbreviations: CS, caesarean section; EMCS, emergency caesarean section; ELCS, elective caesarean section; FFP, fresh frozen plasma; PPH, postpartum hemorrhage; SVD, spontaneous vaginal delivery; $\mathrm{UCH}$, university college hospital; TTIs, transfusion transmissible infections; PCV, packed cell volume

\section{Introduction}

Blood transfusion remains a life-saving practice to millions of women annually; it is an adjunct to good obstetric care, with obstetric hemorrhage and severe anaemia being some of the most common indications. ${ }^{1}$ Obstetric emergencies associated with urgent need for blood may grow direr if not managed effectively. ${ }^{2}$ Globally 127,000 maternal deaths are caused by obstetric hemorrhage annually, and it is the leading cause of maternal mortality in the developing world. ${ }^{3,4}$ Furthermore, massive and fatal obstetric haemorrhages occur in 3 to $5 \%$ of deliveries and in 30 to 50 per 100,000 deliveries, transfusion of blood products is required. ${ }^{4}$ Hemorrhage during labour, delivery, pregnancy and postpartum accounts for $34 \%$ of maternal deaths in West Africa ${ }^{5}$ and the overall outcome is more severe against a backdrop of severe anaemia in pregnancy and possibly a poor marrow reserve. ${ }^{6}$ Quite a lot of these deaths in developing nations are preventable, as demonstrated by an audit of five hospitals in Senegal- $48 \%$ of deaths were rated avoidable and $25 \%$ were considered probably avoidable. Unlike in many other specialities, the majority of blood transfusions in obstetric practice are in response to unexpected hemorrhage in seemingly healthy patients. ${ }^{7}$ Transfusion practice differs between hospitals and countries due to case mix, variation in clinical practice and blood transfusion guidelines with transfusion rates of 0.1 to $2.9 \%^{8-}$ ${ }^{10}$ Several studies have also found the likely reduction in transfusion rates without affecting patients' outcome in disciplines where there is extensive discrepancy in transfusion rates between hospitals. ${ }^{11}$ In order to attain good outcomes, blood transfusions have to be done cautiously and appropriately because of the associated adverse effects. The availability of adequate and safe blood has been a major challenge in developing countries due to poor facilities for storage, inappropriate blood ordering and blood component preparation. ${ }^{12}$ In sub-Saharan Africa, inadequate blood transfusion contributes to $26 \%$ of maternal hemorrhagic deaths and globally up to 150,000 pregnant women die due to lack of access to safe blood..$^{13}$ According to the WHO, blood safety is attained when all individuals have access to blood \& blood products that are as safe as possible, available at reasonable cost, adequate to meet the needs of all patients, transfused only when necessary and provided as part of a sustainable blood programme within the existing health care system. ${ }^{14}$ 
The unavailability of safe blood supply has a significant impact on the rates of administration of life-saving blood transfusions. With $5 \%$ of HIV infection in low and middle income countries coming from transfusion of HIV contaminated blood, it is not surprising that both physician and public sentiment maintains a healthy skepticism of donor supply. ${ }^{15}$ Rapid access to adequate and safe supplies of blood for transfusion is therefore absolutely critical to prevent deaths due to obstetric hemorrhage. Safe blood donors are the cornerstone of a safe and adequate supply of blood and blood products. The safest blood donors are voluntary, non-remunerated blood donors from low-risk populations. Despite this, family/replacement and paid donors, which are associated with a significantly higher prevalence of TransfusionTransmissible Infections (TTIs) including HIV, hepatitis B, hepatitis $\mathrm{C}$, syphilis and Chagas disease, still provide more than $50 \%$ of the blood collected in developing countries. ${ }^{6}$ Presently, emphasis is laid on an individualized method of management with the aim of reducing the need for transfusion, thus avoiding its adverse effects. ${ }^{16}$ To this end, this study aims to explore transfusion rate, identify the common indications for transfusion and review blood products administration in obstetrics patients at the University College Hospital, Ibadan.

\section{Materials and methods}

The medical records of obstetrics patients that were transfused between January 2009 and December 2014 in University College Hospital (UCH), Ibadan, Nigeria were retrieved and reviewed. Ethical approval was garnered from the College of Medicine/UCH IRB. UCH is a tertiary institution and serves as a referral centre for hospitals smaller and more distant hospitals in the country. Information was extracted from the medical records using a pro-forma. Demographic characteristics, obstetrics history, diagnosis and transfusion details were obtained. In this study, booked patients were regarded as those who received ante natal care at the $\mathrm{UCH}$, Ibadan while un-booked patients were those who did not access antenatal care at all, or received care outside of UCH. Blood transfusion rate denotes both the transfusion of blood and other blood products (Packed cell, Fresh frozen plasma, cryoprecipitate). Data were entered and analysed using SPSS version 20.

\section{Results}

During the six year period, 597 obstetric patients were transfused with blood or blood products across the 21,208 births and 27,019 antenatal and birth admissions. Of these, the medical records of $565(94.6 \%)$ were retrieved and analysed. The overall transfusion rate was $2.2 \%$. Among the 565 obstetric patients, over two-thirds $(72.9 \%)$ were un-booked, 439(78.7\%) were transfused at delivery and 126 $(22.3 \%)$ were transfused during pregnancy. The mean age of the patients was $30 \pm 5.7$ years with majority, $172(30.4 \%)$ being between 30 and 34years. The median parity was 2(range 0-9) while $120(23.0 \%)$ were primigravidae (Table 1).

There was history of previous CS in 106(18.8\%) women and out of these, $83(78.3 \%)$ had CS done only once while just $2(1.8 \%)$ had undergone CS three times before. Transfusion rate was higher $268(61.0 \%)$ among patients who delivered through CS compared with $165(37.6 \%)$ who had spontaneous vaginal delivery (Figure 1). A higher proportion, 214(48.7\%), of the obstetrics patients that were transfused during delivery had Emergency Caesarean Sections (EMCS), more than one-third 165(37.6\%) delivered via spontaneous vaginal delivery, 54(12.3\%) delivered via elective CS (ELCS) and only $6(1.4 \%)$ had operative vaginal delivery.
Table I Demographic and obstetric characteristics of patients

\begin{tabular}{|c|c|c|}
\hline Variable & Frequency (565) & Percent (\%) \\
\hline \multicolumn{3}{|l|}{ Age } \\
\hline$<19$ & 18 & 3.2 \\
\hline $20-24$ & 82 & 14.5 \\
\hline $25-29$ & 150 & 26.5 \\
\hline 30-34 & 172 & 30.4 \\
\hline $35-39$ & 123 & 21.8 \\
\hline$\geq 40$ & 20 & 3.5 \\
\hline Mean \pm SD & $30 \pm 5.70$ & \\
\hline \multicolumn{3}{|c|}{ Marital Status } \\
\hline Single & 18 & 3.2 \\
\hline Married & 547 & 96.8 \\
\hline \multicolumn{3}{|l|}{ Parity } \\
\hline 0 & 130 & 23 \\
\hline I & 142 & 25.1 \\
\hline 2 & 123 & 21.8 \\
\hline 3 & 68 & 12 \\
\hline 4 & 48 & 8.5 \\
\hline$>4$ & 54 & 9.6 \\
\hline \multicolumn{3}{|c|}{ Booking Status } \\
\hline Booked & 153 & 27.1 \\
\hline Un-booked & 412 & 72.9 \\
\hline \multicolumn{3}{|c|}{ History of Previous CS } \\
\hline Yes & 106 & 18.8 \\
\hline No & 459 & 81.2 \\
\hline \multicolumn{3}{|c|}{ Number of Previous CS $* *$} \\
\hline 1 & 83 & 78.3 \\
\hline 2 & 21 & 19.8 \\
\hline 3 & 2 & 1.9 \\
\hline \multicolumn{3}{|c|}{ History of blood transfusion } \\
\hline Yes & 53 & 9.4 \\
\hline No & 512 & 90.6 \\
\hline
\end{tabular}

$* *_{n}=106 ; C S$, caesarean section

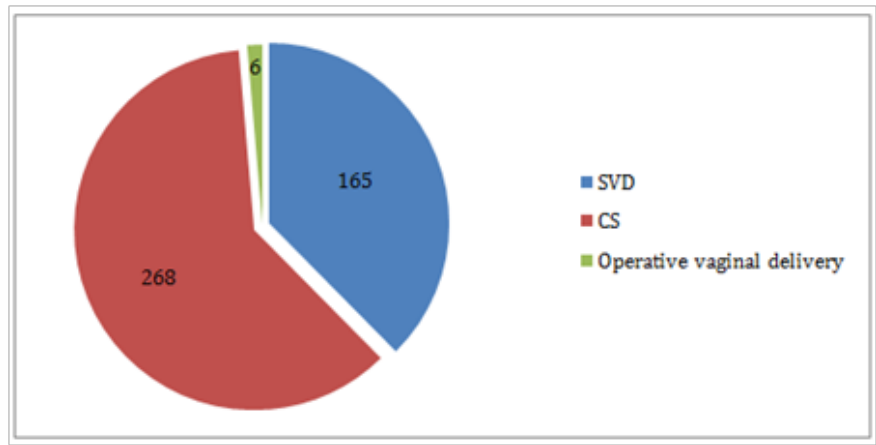

Figure I Mode of delivery of transfused patients.

SVD, spontaneous vaginal delivery

CS, caesarean section 
Fifty-three of the obstetrics patients had been transfused before in previous pregnancies or deliveries. More than two-thirds, 478(84.6\%) were transfused with whole blood or blood products with 466 of them $(82.5 \%)$ receiving whole blood. 5(0.9\%) received Fresh Frozen Blood (FFP), 5(0.9\%) received packed cell blood, and 2(0.4\%) received cryoprecipitate. $87(15.4 \%$ ) had a combination of blood and blood products (Table 2 ). While the majority $183(32.6 \%)$ received double unit-transfusions, $178 \quad(31.7 \%)$ received single unit-transfusions (Table 3).

Table 2 Blood and blood products transfused

\begin{tabular}{lll}
\hline Blood products & Frequency & Percent \\
\hline Whole blood & 466 & 82.5 \\
Fresh frozen blood (FFP) & 5 & 0.9 \\
Packed cell & 5 & 0.9 \\
Cryoprecipitate & 2 & 0.4 \\
Whole blood and FFP & 79 & 14 \\
FFP and Packed cell & 2 & 0.4 \\
Whole blood, FFP and Packed cell & 2 & 0.3 \\
Whole blood and Packed cell & 4 & 0.7
\end{tabular}

Table 3 Indication for transfusion and units of blood transfused

\begin{tabular}{|c|c|c|c|c|}
\hline \multirow{2}{*}{ Indication } & \multicolumn{3}{|c|}{ Number of blood units transfused } & \multirow{2}{*}{ Total (\%) } \\
\hline & $1 \%$ & $2 \%$ & $\geq 3 \%$ & \\
\hline Anaemia & $109(29.5)$ & $120(32.4)$ & $14 \mid(38.1)$ & $370(65.5)$ \\
\hline $\mathrm{PPH}$ & $67(36.4)$ & $60(32.6)$ & $57(31.0)$ & $184(32.6)$ \\
\hline Abruptio placenta & 0 & 0 & $3(100)$ & $3(0.5)$ \\
\hline Severe Malaria & $2(50.0)$ & $\mathrm{I}(25.0)$ & $I(25.0)$ & $4(0.7)$ \\
\hline Placenta previa & $0(0.0)$ & $2(50.0)$ & $2(50.0)$ & $4(0.7)$ \\
\hline Total & I78(3|.5) & $183(32.4)$ & $204(36.1)$ & 565 \\
\hline
\end{tabular}

$\mathrm{PPH}$, post partum hemorrhage

The commonest indication for blood transfusion was anaemia $370(65.5 \%)$ followed by PPH 184(32.6\%). All three patients with abruptio placentae had three or more units of blood transfused (Table 3). The mean post transfusion Packed Cell Volume (PCV) was 25.9 \pm 8.6 , although, this was higher $(26.1 \pm 4.5)$ among booked patients. Estimated blood loss during delivery was significantly higher among un-booked patients than in booked patients $(\mathrm{P}<0.01)$ (Table 4).

Table 4 Mean PCV, estimated blood loss and blood transfusion of the patients

\begin{tabular}{lllll}
\hline Variable & Booked & Un-booked & t-test & P-value \\
\hline $\begin{array}{l}\text { Pre-transfusion } \\
\text { PCV }\end{array}$ & $24.9 \pm 6.9$ & $22.3 \pm 3.0$ & 3.9 & $<0.0001$ \\
$\begin{array}{l}\text { Estimated blood } \\
\text { loss }\end{array}$ & $1186.1 \pm \mid 555.2$ & $155 I .1 \pm|4| .0$ & 3.18 & $<0.01$ \\
$\begin{array}{l}\text { Post transfusion } \\
\text { PCV }\end{array}$ & $26 . I \pm 4.5$ & $25.9 \pm 2 I .8$ & 0.07 & 0.94 \\
\hline
\end{tabular}

$\mathrm{PCV}$, packed cell volume

\section{Discussion}

Obstetric hemorrhage is one of the leading causes of maternal morbidity and mortality and the second leading cause for transfusion following anaemia. Coincidentally with the findings reported by Patel et al. ${ }^{17}$ and Chhabra et al., ${ }^{18}$ this study also finds that hemorrhage and anaemia were the major indications for blood transfusion in the obstetric patients reviewed. ${ }^{17,18}$ The overall transfusion rate of $2.2 \%$ is similar to the transfusion rate of $2.27 \%$ reported in Finland and falls within the range of 0.9 to $2.9 \%$ reported by Patel et al in Australia. ${ }^{7,17}$ However, the obtained rate was significantly lower than that of the rates of $10.5 \%$ and $12.1 \%$ documented in two tertiary hospitals in Nigeria, pointing to an inconsistency in administration of blood products in country. ${ }^{15}$ This difference could be explained by different transfusion practices among institutions, low availability of donor blood in our environment, or case mix. Ideally, minimal blood use is recommended in standardized healthcare facilities.

This study found that the transfusion rate at delivery was high. Among patients who had CS, the transfusion rate was nearly $50 \%$, a significantly higher rate than that obtained from previous studies citing rates from $17.8-31 \% .{ }^{3,19,20}$ The high rate could be a result of the complexity of cases seen at this particular facility, given its status as a tertiary institution and referral centre. Another possible explanation for the high rate is that most of the women were un-booked patients who were referred to the hospital after several attempts to control the situation by unskilled health workers or birth attendants. By the time these patients presented to the hospital, they were critically ill and in desperate need of transfusion. ${ }^{15}$

We also found that the transfusion rate was higher among patients who had emergency CS. This finding was consistent with findings from the studies of Owonikoko et al., ${ }^{3}$ Menacker et al., ${ }^{21}$ Enohumah et al..$^{22}$ Patients with abruptio placentae received more units of blood, in keeping with some studies which noted that abruptio placentae with blood loss is one of the causes of hemorrhage in pregnancy and can be life threatening. ${ }^{3,23}$ The majority of the transfused patients in this study received whole blood. This finding contradicts that of Patterson et al. ${ }^{7}$ in which transfusion of blood products like platelets and coagulation factors surpassed that of whole blood in tertiary hospitals. ${ }^{7}$ A lack of availability of these products at this facility could explain this discrepancy. However, the fact that most of the transfusions at this facility were done on an emergency basis reduced the chances of getting the correct components in a timely manner. Most of the patients had only one unit of blood transfused despite the need for more units in view of the estimated blood loss at delivery or their low hematocrit values. This could not be achieved because the cost of blood procurement, screening, and storage is high; and blood donation is infrequent. These losses could be circumvented by employing certain strategies that make the best use of current clinical guidelines.

It is highly recommended that national blood transfusion and hospital-based centres are upgraded from mere blood donation loci to state-of-the-art transfusion facilities. The regular donor system should be balanced and retained until we achieve one hundred percent nonremunerable voluntary blood donor status like has been accomplished in other African nations such as Kenya and Uganda. ${ }^{24}$ Making the right component of blood available for the right person and ensuring precise indications for prescribing transfusions to children, pregnant women and other adults with severe anemia will bring our community closer to achieving satisfactory clinical use of blood. Additionally, 
techniques which allow for multiplicity of blood products from a single source can help ensure that a limited supply of whole blood is far-reaching to patients in need. The platelet-rich plasma and buffy coat methods, and the apheresis platelet concentrate method are laboratory approaches to separating and obtaining blood in its component parts to be distributed. Furthermore, the use of autologous transfusion should be encouraged.

\section{Conclusion}

In conclusion, un-booked patients had the highest transfusion rate when compared to other obstetric patients. Patients that delivered through Caesarean Section had a greater indication for transfusion than those who delivered vaginally. Anaemia was the commonest indication for transfusion. If adequate pre conceptional and antenatal care was more widely available, coupled with identification of risk factors and treatment of anaemia, these high rates could be reduced. This study highlights the importance of individualized care for patients, in addition to creating and conserving adequate blood donor supplies to meet the needs of populations vulnerable to ischemic insult and obstetric emergencies.

\section{Acknowledgements}

None.

\section{Conflict of Interest}

The authors certify that they have no affiliations with or involvement in any organization or entity with any financial interest (such as honoraria, educational grants, participation in speakers' bureaus, membership, employment, consultancies, stock ownership or other equity interest and expert testimony or patent-licensing arrangements) or non-financial interest (such as personal or professional relationships, affiliations, knowledge or beliefs) in the subject matter or materials discussed in this manuscript.

\section{References}

1. Jou HJ, Hung HW, Yan YH, et al. Risk factors for blood transfusion in singleton pregnancy deliveries in Taiwan. Int $J$ Gynaecol Obstet. 2012;117(2):124-127.

2. Pavord S, Myers B, Robinson S, et al. UK guidelines on the management of iron deficiency in pregnancy. Br J Haematol. 2012;156(5):588-600.

3. Owonikoko KM, Adeoye A, Adeyemi AS, et al. Assessment of blood transfusion practices at caesarean section in a teaching hospital in southwestern nigeria. International Journal of Medicine and Pharmaceutical Sciences. 2014;4(6):69-76.

4. Matsunaga $\mathrm{S}$, Seki $\mathrm{H}$, Ono $\mathrm{Y}$, et al. A retrospective analysis of transfusion management for obstetric hemorrhage in a Japanese obstetric center. ISRN Obstet Gynecol. 2012;2012:854064.

5. Akingbola TS, Adewole IF, Adesina OA, et al. Haematological profile of healthy pregnant women in Ibadan, south-western Nigeria. $J$ Obstet Gynaecol. 2006;26(8):763-769.

6. Bates I, Chapotera GK, McKew S, et al. Maternal mortality in subSaharan Africa: the contribution of ineffective blood transfusion services. BJOG. 2008;115(11):1331-1339.
7. Patterson JA, Roberts CL, Bowen JR, et al. Blood transfusion during pregnancy, birth and the postnatal period. Obstet Gynecol. 2014;123(1):126-133.

8. Patterson JA, Roberts CL, Isbister JP, et al. What factors contribute to hospital variation in obstetric transfusion rates? Vox Sang. 2015;108(1):37-45.

9. Lutomski JE, Greene RA, Byrne BM. Severe maternal morbidity during childbirth hospitalisation: a comparative analysis between the Republic of Ireland and Australia. Eur J Obstet Gynecol Reprod Biol. 2012;163(2):148-153.

10. Heinonen A, Gissler M, Riska A, et al. Loop electrosurgical excision procedure and the risk for preterm delivery. Obstet Gynecol. 2013;1121(5):1063-1068.

11. Murphy MF, Stanworth SJ, Yazer M. Transfusion practice and safety: current status and possibilities for improvement. Vox Sang. 2011;100(1):46-59.

12. Musa AU, Ndakotsu MA, Hassan AA, et al. Pattern of blood transfusion request and utilization at a Nigerian University Teaching Hospital. Sahel Med J. 2014;17(1):19-22.

13. Dunn JS, Nawal M (2011) The use of blood in obstetrics and gynecology in the developing world. Rev Obstet Gynecol 4(2): 86-91.

14. World Health Organization. Safe blood and blood products: Distance learning materials. USA; 2009.

15. Anorlu RI, Orakwe CO, Abudu OO, et al. Uses and misuse of blood transfusion in obstetrics in Lagos, Nigeria. West Afr $\mathrm{J}$ Med. 2003;22(2):124-127.

16. Isbister JP. The three-pillar matrix of patient blood management-an overview. Best Pract Res Clin Anaesthesiol. 2013;27(1):69-84.

17. Patel VP, Patel RV, Shah PT, et al. Study of role of blood transfusion in obstetric emergencies. Int J Reprod Contracept Obstet Gynecol. 2014;3(4):1002-1005.

18. Chhabra S, Namgyal A. Rationale use of blood and its components in obstetric-gynecological practice. Journal of Mahatma Gandhi Institute of Medical Sciences. 2014;19(2):93-99.

19. Akinola OI, Fabamwo AO, Tayo AO, et al. Evaluation of blood reservation and use for caesarean sections in a tertiary maternity unit in south western Nigeria. BMC Pregnancy Childbirth. 2010;10:57.

20. Bilal SN, Yasmin F, Akhtar S. Frequency and indications of cesarean section in a tertiary care maternity unit. Journal of Postgraduate Medical Institute. 2005;19(4).

21. Menacker F, Declercq E, Macdorman MF. Cesarean delivery: background, trends, and epidemiology. Semin Perinatol. 2006;30(5):235-241.

22. Enohumah KO, Imarengiaye CO. Factors associated with anaesthesiarelated maternal mortality in a tertiary hospital in Nigeria. Acta Anaesthesiol Scand. 2006;50(2):206-210.

23. Kinoshita T, Takeshita N, Takashima A, et al. A case of life-threatening obstetrical hemorrhage secondary to placental abruption at 17 weeks of gestation. Clin Pract. 2014;4(1):605.

24. Bantayehu D. Knowledge, attitude, and practice of voluntary blood donation and associated factors among health care providers in Addis Ababa health facilities, ethiopia. Occup Med Health Aff. 2015;3(4):209. 